\title{
ANENCEFALIA E TRANSPLANTE DE ÓRGÃOS
}

\author{
Aline Albuquerque S. de Oliveira \\ Advocacia-Geral da União, Distrito Federal, Brasil. \\ alineaoliveira@hotmail.com
}

\begin{abstract}
Resumo: O transplante de órgãos em neonatos anencéfalos apresenta-se como um conflito ético. Os neonatos portadores de anencefalia são, sob o critério de morte encefálica adotado no artigo $3^{\circ}$ da Lei $\mathrm{n}^{\circ}$ 9.434, de 4 de fevereiro de 1997, considerados pessoas vivas, uma vez que morte encefálica implica a falência, inclusive, do tronco encefálico, o que não ocorre no caso do anencéfalo. Entretanto, a Resolução n ${ }^{\circ}$ 1.752/04, do Conselho Federal de Medicina (CFM), estabelece a permissão para o médico realizar o transplante de órgãos ou tecidos do anencéfalo, após seu nascimento. A adoção de tal medida pelo CFM implica a morte do neonato anencéfalo praticada pelo médico, uma vez que o mesmo se encontra vivo, conforme os parâmetros legais apontados. O dilema se instaura em razão de posicionamentos éticos distintos. O CFM consolidou o entendimento daqueles que entendem serem inaplicáveis e desnecessários os critérios de morte encefálica ao neonato nessas condições, visando à realização de transplante de órgãos, ou seja, postura nitidamente utilitarista. O presente texto defende o respeito à pessoa enquanto eixo axiológico central de toda discussão bioética.
\end{abstract}

Palavras-chave: Anencefalia. Transplante de órgãos. Bioética. Valores.

\begin{abstract}
Organ's transplant in neonates without brain presents an ethical conflict. Neonates without encephalon are, under the criterion of brainy death adopted on article III of Law No. 9,434, February 4, 1997, considered alive, whereas brainy death implies necessarily the failure of the brainstem, what does not happen in the brainless case. Nevertheless, the Federal Medicine Council's Resolution No. 1752/ 04 establishes an allowance so that the physician can realize the organs' transplant and/or brainless neonate's tissue, after her birth. The adoption of such a measure by the FMC implies the neonate's death carried out by the doctor, since she is alive, according to the legal parameters pointed out. The dilemma begins because there are distinct ethical positions. The FMC has consolidated the understanding that the rules of brain death are not applicable and unnecessary to the neonate under such conditions, aiming at the realization of transplant of organs, i.e., posture clearly utilitarian. This text defend the respect to the person as long as central axiological axis in the whole bioethical discussion.
\end{abstract}

Key words: Anencephaly. Transplant of organs.Bioethical. Values. 
presente trabalho possui como escopo contribuir para o debate acerca do anencéfalo enquanto doador de órgãos. A despeito da incidência de tal malformação não ser expressiva, logo, não constituir fator determinante no aumento de órgãos a serem transplantados, importa a abordagem do tema para considerações de outra ordem. No campo da bioética, ferramenta teórica utilizada para o esquadrinhamento do presente tema, verificam-se posiciona-mentos divergentes quanto à temática, notadamente quanto à postura ética adotada na Resolução no 1.752/04 do Conselho Federal de Medicina (CFM).

Desta forma, malgrado o número de anencéfalos não ser expressivo para o quadro de transplante de órgãos no Brasil, é relevante o debate acerca da sua condição de doador, na medida em que escolhas que caminhem em direções distintas refletem opções éticas sobre a morte e principalmente sobre a vida. Ao reconhecer a relevância da temática, traremos ao presente trabalho fundamentos em bioética que permitam a melhor compreensão da matéria e contribuam para reflexão sobre um tema que demarca escolhas de considerável repercussão social.

\section{Anencefalia e Transplante de Órgãos}

Não obstante a edição da Resolução CFM no 1.752/04, o Conselho apresentou entendimentos dissonantes quanto à temática, conforme pode ser observado no Processo-Consulta $n^{0}$ 1.839/98. Verifica-se, nesse processo, que foi considerado aceitável o transplante de órgãos do anencéfalo após a confirmação do diagnóstico de morte encefálica. Entretanto, o Relator de Vista no mesmo processo-consulta, emitiu parecer no sentido de que é possível a retirada de órgãos do anencéfalo com a anuência dos genitores, mesmo que ainda não haja diagnóstico de morte encefálica. Assim, diante da discrepância de posicionamento presente em ambos pareceres, o Conselho Federal de Medicina promoveu no dia 16 de junho de 2004 o Fórum Nacional Sobre Anencefalia e Transplante de Órgãos, com a presença de médicos conhecedores do tema, bem como do presidente da Sociedade Brasileira de Bioética, do coordenador da Comissão Nacional de Ética em Pesquisa, e outros convidados de equânime relevância. Nessa ocasião, ficou patente a polêmica em torno da temática e as conseqüências éticas inerentes aos posicionamentos adotados. 


\section{Anencefalia}

O primeiro caso de transplante de órgãos com doador anencéfalo foi relatado em 1967, contudo, apenas foram destacados os aspectos científicos, sem preocupação com os deslindes éticos que o procedimento suscitava. (COMITATO NAZIONALE PER LA BIOETICA, 2004). Atualmente, nota-se uma mudança na percepção na questão do doador anencéfalo, que se reflete, inclusive, no vocábulo anecephaly do Index Medicus, o qual, após 1984, ampliou suas referências para abarcar os desdobramentos éticos da problemática (COMITATO NAZIONALE PER LA BIOETICA, Op. cit.).

Anencefalia, segundo o Dicionário Mosby (1996, significa a ausência congênita de encéfalo e medula espinhal, quadro incompatível com a vida. A anencefalia é uma rara malformação do tubo neural que se dá entre as 16

a e $26{ }^{\text {a }}$ semanas de vida, e sua incidência varia entre 0,5 e 4,5 por 1.000 nascimentos (INSTITUTO NACIONAL CENTRAL ÚNICO COORDINADOR DE ABLACIÓN E IMPLANTE, 2004). No anencéfalo se verifica a presença do tronco encefálico, porém a ausência dos hemisférios e do cerebelo pode ser variável. É importante ressaltar que a anencefalia é uma malformação que se processa gradativamente, passando de um quadro menos grave para um quadro de indubitável malformação, devendo ser afastada qualquer classificação rígida de anencefalia (COMITATO NAZIONALE PER LA BIOETICA, Op. cit.). Igualmente, pode-se afirmar que a atividade do tronco cerebral pode ser suficiente, nos casos menos graves, para lhe garantir uma primitiva consciência.

O diagnóstico de anencefalia pode ser feito entre a $12^{\mathrm{a}}$ e $18^{\mathrm{a}}$ semanas de gestação, bem como se constata sua presença, com maior freqüência, na gravidez de mulheres com mais de 35 anos de idade. Se entre 40 e $60 \%$ dos anencéfalos nascem vivos, após o nascimento apenas $8 \%$ sobrevivem mais de uma semana, $1 \%$ vive entre 1 e 3 meses. O Comitato Nazionale per la Bioetica relata ainda um caso de sobrevivência até 14 meses e outros dois entre 7 e 10 meses (COMITATO NAZIONALE PER LA BIOETICA, Op. cit.).

Assim, o anencéfalo, embora haja algumas variações no diagnóstico, apresenta uma anomalia congênita e irreversível, sendo possível sua sobrevivência apenas por um lapso temporal determinado. Dentro desse quadro, após o nascimento do anencéfalo geralmente não é empregado nenhum meio extraordinário de cura, isto é, recorre-se somente às terapias suficientes para lhe oferecer uma condição de vida digna e compatível com seu estado de saúde. 


\section{A morte encefálica}

O critério utilizado para se determinar a morte de um ser humano foi, durante alguns séculos, a parada cárdio-respiratória. O conceito de morte encefálica surge no final da década de cinqüenta, a partir dos avanços tecnológicos ${ }^{1}$ no processo de morte, e implica a cessação irreversível das funções dos hemisférios cerebrais e do tronco encefálico (INSTITUTO NACIONAL CENTRAL ÚNICO COORDINADOR DE ABLACIÓN E IMPLANTE, Op. cit.). Acrescente-se que a ampliação das possibilidades de se recorrer aos transplantes ensejou a mudança de parâmetro para a morte, na medida em que o critério da parada cárdio-respiratória não permitia a utilização de órgãos comprometidos com a falência circulatória. Dessa forma, por meio do informe do Comitê da Escola de Medicina de Harvard, publicado em 1968, foi proposto o coma irreversível como critério de morte. Esse documento foi decorrência de uma consulta apresentada por médicos do Massachusetts General Hospital ao Ad Hoc Committee of the Harvard Medical School, dirigido por Henry Beecher, com o objetivo de definir quando seria razoável a realização do transplante de órgãos (GHERARDI, 2004).

Em 1981, nos Estados Unidos, os critérios para a morte encefálica foram ampliados para as crianças com cinco anos ou mais e, em 1987, foram incluídos aquelas com sete dias ou mais de vida (CASELLA, 2004).

No critério cardio-respiratório, para constatar-se a morte, considera-se a parada cardíaca; posteriormente há a cessação das atividades de todas as estruturas que compõem o encéfalo. Na morte com critério neurológico ou encefálico, a função respiratória pode ser suprida por meios artificiais bem como o coração pode ser mantido por drogas que permitam a permanência dos batimentos por algum tempo. Então, na denominada morte encefálica, não há presença dos reflexos e das funções comandados pelos hemisférios cerebrais e tronco encefálico. Para se determinar sua ocorrência, são observados determinados critérios estabelecidos pelo referido Comitê de Harvard, em 1968, dentre os quais importa destacar, para os fins do presente trabalho, a ausência de reflexo e de respiração espontânea. Além desses critérios, o Memorial Hospital for Cancer and Allies Diseases, aponta também a ausência de funções do tronco cerebral (PIANETTI FILHO, 2001).

\footnotetext{
${ }^{1}$ Considere-se que "mecanismos modernos de ressuscitação e principalmente de manutenção da circulação e oxigenação cerebral foram incluídos no arsenal terapêutico" (PIANETTI FILHO, 2001).
} 
O Conselho das Organizações Internacionais de Ciências Médicas, ligado à Organização Mundial da Saúde (OMS) e à UNESCO, reuniu-se em 1968, em Genebra e estabeleceu critérios para a morte encefálica, considerando especificamente o falecimento do doador. Dentre estes critérios destacam-se a paralisação espontânea da respiração, perda de todo sentido ambiente, debilidade total dos músculos e colapso da pressão sanguínea não mais mantida artificialmente (ANAMI, 2000).

$\mathrm{Na}$ anencefalia e em algumas lesões das estruturas encefálicas, como no Estado Vegetativo Persistente (EVP), o tronco encefálico conserva seus reflexos, como a respiração, a regulação cardiovascular e a temperatura (INSTITUTO NACIONAL CENTRAL ÚNICO COORDINADOR DE ABLACIÓN E IMPLANTE, Op. cit.).

Com relação ao critério cerebral, se verifica uma subdivisão que se refere à morte do cérebro total (whole brain), que pressupõe a falência absoluta dos hemisférios cerebrais e do tronco encefálico, e à morte do cérebro superior ou neocórtex (higer brain formulation). Importa anotar que se o critério utilizado fosse da falência do neocórtex, pacientes em EVP, com demências profundas e os anencéfalos, seriam considerados mortos. Contudo, esse critério não tem conseguido aceitação jurídica no mundo (INSTITUTO NACIONAL CENTRAL ÚNICO COORDINADOR DE ABLACIÓN E IMPLANTE, Op. cit.).

O critério adotado no Brasil para fins de transplante, é a morte encefálica, nos termos do artigo $3^{\circ}$ da Lei $\mathrm{n}^{\circ}$ 9.434, de 4 de fevereiro de 1997, o qual estabelece que a retirada post mortem de tecidos, órgãos ou partes do corpo humano, destinados a transplante ou tratamento, deverá ser precedida de diagnóstico de morte encefálica, com critérios clínicos e tecnológicos definidos por resolução do CFM. A Resolução CFM no 1.480, de 1997, apresenta regulamentação da citada lei e estatui os critérios de morte encefálica consoante aqueles vigentes em quase todo os países do mundo (CASELLA, Op. cit.). No Brasil, portanto, apenas a morte encefálica pode ser utilizada como critério, afastando-se qualquer tentativa de emprego da falência do neocórtex.

De acordo com a citada Resolução do CFM, a morte encefálica deve ser determinada a partir do coma aperceptivo com ausência de atividade motora supra-espinal e apnéia. Com a definição do coma "o paciente deve ser avaliado quanto à resposta motora, reflexos do tronco cerebral e teste de apnéia" (ANAMI, Op. cit.).

Não obstante a adoção do critério da morte encefálica pela legislação 
brasileira, não há ainda consenso em torno da sua definição e diagnóstico (COMITATO NAZIONALE PER LA BIOETICA, Op. cit.), notadamente quando se trata de crianças com menos de sete dias.

\section{O anencéfalo como doador de órgãos}

Tratando-se de neonato anencéfalo, a demonstração de sua morte encefálica é extremamente dificultosa em razão da ausência de domínio sobre sua neurofisiologia, bem como da malformação inerente à sua condição física. O exame para se configurar o traçado linear de eletroencefalograma não é possível, em função da anatomia da sua estrutura encefálica. Da mesma forma, os reflexos do tronco variariam de acordo com a caracterização da malformação, sendo os exames clínicos para atestar a atividade do tronco cerebral de confiabilidade duvidosa e de difícil interpretação (COMITATO NAZIONALE PER LA BIOETICA, Op. cit.). Contudo, Casella afirma que existem exames que podem ser utilizados como instrumento confirmatório de morte encefálica em pacientes com anencefalia" (CASELLA, Op. cit.).

As dificuldades relacionadas ao anencéfalo também podem ser consideradas para o neonato, uma vez que não há entendimento unívoco acerca da potencialidade do encéfalo do mesmo, pois, pode ser entendido como um órgão em formação com potencialidade variável (COMITATO NAZIONALE PER LA BIOETICA, Op. cit.).

Assim, diante da ausência de conhecimentos sobre o desenvolvimento neuro-fisiológico do neonato, bem como do anencéfalo, é importante estabelecer os limites dos critérios utilizados para definir a morte encefálica nesses casos.

Observa-se que, conforme a Resolução CFM no 1.480/97, não há consenso sobre a aplicabilidade dos critérios dispostos naquele ato normativo em crianças menores de sete dias e prematuros. Desse modo, considerando as questões atinentes ao fluxo cerebral e ao EEG não se pode confiar nos critérios apontados como seguros para garantir a efetiva morte cerebral do neonato. Deveriam ser utilizados, nesses casos, apenas os critérios clínicos também previstos na mencionada Resolução, tais como ausência de atividade motora supra-espinal e apnéia, mas observando a idade mínima de sete dias. Entretanto, cabe ressaltar que, o EEG e o FSC são compatíveis com os casos de anencefalia (CASELLA, 2004).

Com relação ao anencéfalo, já foi sugerido que se avaliasse a presença 
de respiração espontânea, a atividade do tronco cerebral mais importante, sendo a sua ausência critério suficiente para determinar a falência do tronco cerebral (COMITATO NAZIONALE PER LA BIOETICA, Op. cit.). Nesta linha, Moreira sustenta que "nos anencefálicos a constatação da morte encefálica através de critérios clínicos poderia ser feita através de protocolos específicos adaptados para essas situações" (MOREIRA, 2004). O problema que se poderia apontar correlacionado a esse critério, seria a constituição de uma categoria de análise da morte, específica para a anencefalia, separando-a e inserindo-a em uma condição singular.

Retomando os pareceres emitidos por membros do CFM, nota-se que o Relator Consultor argumenta que se um anencéfalo neonato fosse utilizado como doador logo após o nascimento, se estaria sacrificando-o em benefício de outro, uma vez que possui tronco cerebral funcionando. Destaca, ainda, a alteração de posicionamento da Associação Médica Americana, que, atualmente, permite a doação de órgãos pelo anencéfalo apenas após a constatação de sua morte encefálica. O Relator de Vista, no mesmo processo-consulta, sustenta que caso se aguardem os sete dias, bem como o resultado positivo dos exames clínicos para a constatação de morte encefálica, seria inviável a utilização dos órgãos do anencéfalo, uma vez que estariam em hipoxemia, inúteis para o transplante. Assim, ao se considerar a fila de crianças que aguardam um órgão para a sobrevivência, bem como a incompatibilidade vital que o anencéfalo apresenta, seria aceitável a retirada de órgãos do mesmo logo após sua expulsão do útero materno.

Na Consulta $n^{\circ}$ 8.905/98, do Conselho Regional de Medicina do Estado de São Paulo, o Relator Consultor proferiu parecer no sentido de que sejam asseguradas as condições cárdio-respiratórias do anencéfalo para que seja viável o transplante, enfatizando que, cientificamente, não há perspectiva de vida para o mesmo.

Diante das dificuldades de se aplicar os critérios comumente utilizados para se aferir a morte cerebral em anencéfalos, seja em razão da sua idade de vida, seja em função de sua organização encefálica, sua condição de doador de órgãos revela-se extremamente afetada. Por outro lado, caso fosse empregado no anencéfalo o critério da parada cárdio-respiratória, a doação se restringiria às válvulas cardíacas (INSTITUTO NACIONAL CENTRAL ÚNICO COORDINADOR DE ABLACIÓN E IMPLANTE, Op. cit.).

Assim sendo, o objeto da polêmica gira em torno dos aspectos éticos de uma lei que altere o critério de morte encefálica para o anencéfalo, considerando os aspectos incertos da Resolução CFM n ${ }^{\circ}$ 1.480/97, e venha a adotar 
o parâmetro da falência do neocórtex. ${ }^{2}$ Ressalte-se que admitir o higer brain formulation surtiria efeitos sobre os casos de demência profunda e os Estados Vegetativos Persistentes.

Podemos já afirmar, antes de perquirir os aspectos éticos da questão, que apenas considerando o ordenamento jurídico brasileiro, uma lei federal pode alterar o parâmetro de morte para o caso do anencéfalo. A nenhum outro instrumento normativo cabe fazê-lo, nem mesmo qualquer ato regulador emitido pelo Conselho Federal de Medicina, como foi feito através da Resolução CFM no 1.752/04. Conforme a construção escalonada do ordenamento jurídico há normas superiores e normas inferiores (BOBBIO, 1997). As inferiores retiram seu fundamento de validade das superiores, o que significa que não podem ultrapassar os limites formais e materiais estabelecidos pelas normas superiores. Na estrutura hierárquica do ordenamento brasileiro, as leis federais são superiores em relação a ato normativo oriundo do CFM. Portanto, se de acordo com a Lei $n^{\circ}$ 9.434/97, o critério de morte para qualquer pessoa é a morte encefálica, sua alteração, por meio de uma resolução, equivale à violação de um limite material, logo, uma afronta flagrante aos parâmetros de legalidade.

\section{Aspectos Bioéticos do Anencéfalo como Doador de Órgãos}

A questão acerca do anencéfalo na condição de doador de órgãos, apresenta desdobramentos éticos complexos. Primeiramente, entende-se que importa fazer menção ao status jurídico do anencéfalo. Conforme o artigo $2^{\circ}$ do Código Civil, Lei no 10.406, de 10 de janeiro de 2002, a personalidade civil da pessoa começa do nascimento com vida. Então, no âmbito jurídico, não há dúvidas de que o anencéfalo é uma pessoa, na medida em que nasceu com vida, com todas conseqüências jurídicas advindas do fato de assim ser considerado. Situação diferente do feto anencéfalo, ao qual não é atribuída a condição de pessoa, mas sim a de nascituro, sendo tutelados os direitos que possui enquanto tal. Desta forma, qualquer ato atentatório à integridade física do anencéfalo neonato pode ser considerado como um homicídio ou lesão corporal, condutas tipificadas como criminosas contra a vida humana, regra que não se aplica ao feto anencéfalo. Logo, qualquer

\footnotetext{
2 "Se for considerado desnecessário o diagnóstico de morte encefálica, nos casos de anencefalia, a retirada dos órgãos ou tecidos poderá ser feita logo depois do parto" (FRANCO, 2004).
} 
analogia com a situação do aborto ou com decisões judiciais que o permitem são infundadas, uma vez que a ratio das normas aplicadas às situações apontadas é distinta.

Partindo da premissa de que o anencéfalo é uma pessoa viva, este apenas poderia ser doador de órgãos após sua morte encefálica, salvo se houvesse a alteração do critério de morte para a higer brain formulation. Entretanto, a problemática acerca da adoção do critério da morte do neocórtex acarreta várias implicações éticas. Atualmente, o critério adotado em quase todos os países do mundo é o da morte cerebral; o Brasil seria um dos únicos países a estabelecer um critério diferenciado. À primeira vista poder-se-ia argumentar que não devemos estar sempre a reboque dos outros países. Contudo, malgrado a pertinência de tal assertiva, revela-se importante questionar se a mudança de parâmetro seria um reflexo da vontade informada da sociedade brasileira ou manifestação do posicionamento de alguns especialistas.

Para enfrentar essa questão, deve-se enfatizar que a criação de um critério exclusivo para o anencéfalo acarreta uma zona de incerteza, na medida em que se diferencia a ocorrência da morte em função de uma malformação. É importante questionar se para a sociedade brasileira é aceitável uma regra sobre morte especificamente prevista para uma condição patológica particular. Por outro lado, a mudança do parâmetro de morte, no caso da anencefalia, é motivada pelo transplante de órgãos. Neste caso surge a seguinte questão: de que forma a sociedade brasileira iria perceber a mudança de normas referentes à morte, em função da necessidade menor ou maior do transplante de órgãos?

A Comissão Nacional de Bioética da Itália não aceita o critério da morte neocortical, apresentando como fundamento o fato do paleoncéfalo permanecer íntegro, bem como a capacidade de regulação central homeostática do organismo e a capacidade de respiração autônoma (COMITATO NAZIONALE PER LA BIOETICA, Op. cit.). Assim, também se põe em xeque a aceitabilidade, no Brasil, da morte de seres que ainda estão respirando autonomamente, considerando-se principalmente a repercussão de tal opção para os familiares daqueles que se encontram em Estado Vegetativo Persistente e demência profunda.

Portanto, qualquer alteração do parâmetro de morte para o anencéfalo, deve pressupor a ocorrência de um amplo debate na sociedade brasileira sobre o tema, em razão da sua gravidade. A norma que vier disciplinar a questão, deve ser, antes de tudo, legítima e não representar a visão unilateral de determinadas categorias profissionais. Assim, deve-se trazer o 
questionamento apontado por Costa: "Se o direito é uma ordem normativa que se pretende legitima, quais são os valores que serão utilizados para avaliar essa legitimidade, senão os valores de moralidade e justiça?" (COSTA, 2000). Nesse sentido, a fundamentação axiológica de uma norma que estabeleça critérios de morte e vida não deve se pautar apenas na moralidade de uma entidade representativa de determinada profissão: é forçoso que a sociedade seja convidada a refletir e participar do debate, conferindo legitimidade à regulamentação que vier a ser produzida.

Outra questão que se coloca é acerca do alcance da terapia para a preservação da vida do anencéfalo. A respeito, Garrafa traz uma interrogação preocupante: "quando a criança nascer, apesar do prazo mínimo de vida que terá, deverá ser mantida em tratamento permanente visando ao prolongamento máximo possível de sua 'vida'?" (GARRAFA, 2004). Deve-se estabelecer um limite para a terapia intensiva, eis que se trata de morte inevitável e iminente de paciente privado, na maior parte dos casos, de consciência. Provavelmente a medida a ser adotada mais compatível com a sua condição seria a de confortá-lo com medidas que sustentem condições vitais básicas, evitando a obstinação terapêutica e medidas fúteis (INSTITUTO NACIONAL CENTRAL ÚNICO COORDINADOR DE ABLACIÓN E IMPLANTE, Op. cit.). Segundo Segre:

"nas maternidades as crianças anencefálicas simplesmente não merecem qualquer tipo de recurso excepcional para manter-se com vida. São deixadas nas incubadoras, são alimentadas quando existe alguma capacidade de mamar, e só" (SEGRE, 2004).

No entanto, existem outros posicionamentos. Para Casella deve ser efetuada somente terapia básica com nutrição, hidratação e remoção de secreções até ocorrer a morte encefálica (CASELLA, Op. cit.). Kipper, por sua vez, sugere que se deve-se oferecer suporte vital para o anencéfalo a fim de que sua condição, antes da morte encefálica, não se deteriore e impossibilite a doação de órgãos (KIPPER, 2004).

Assim, nota-se que não se tem uma uniformidade acerca do tratamento que deve ser dispensado ao neonato anencéfalo, na medida em que sua morte é mera questão de tempo. Algumas medidas, todavia, são aceitas como necessárias para se evitar a hipoxemia dos órgãos que podem vir a ser objeto de transplante bem como para permitir que sua sobrevida seja compatível com padrões mínimos de dignidade. 


\section{Considerações Finais}

Cientes de que toda problemática apontada não será facilmente solucionada, apenas tenta-se, a partir das construções teóricas elaboradas por Sève, contribuir para o debate em torno de tal questão (SÈVE, 1994). Primeiramente, deve-se partir do significado ético do termo "pessoa"3. Trabalhando com os referenciais de Sève, consideramos pessoa como um atributo de todos pertencentes ao gênero humano, que lhes confere uma forma-valor. O conceito de pessoa condensa valores extraídos do meio social culminando com o sentido de dignidade. Desse modo, há que se refutar o biologismo e o juridismo, que se sustentam apenas em manifestações fisiológicas ou de consciência, bem como na arbitrariedade da delimitação jurídica. Evitando simplificações, o autor citado propõe a superação das seguranças absolutas representadas pela "verdade biológica" ou pela "normatividade jurídica" (SÈVE, Op. cit.), a fim de que se parta para a construção da pessoa com fulcro na partilha de valores últimos.

O sentido de pessoa traz a universalização do respeito pelo humano, mas não no sentido da uniformidade, que na realidade seria um universalismo artificial, mas sim na perspectiva da construção de condutas equivalentes provocadas por ações multilaterais. Assim, ao se entender que todos que fazem parte do gênero humano são pessoas, qual seria o critério razoável para não se considerar um bebê com uma malformação uma pessoa? Poderse-ia argumentar que o mesmo não tem perspectivas de uma vida futura; no entanto, isso pode ser refutado sob a alegação de que a duração da vida de um ser humano não o desqualifica, não o coloca num patamar inferior. Ou seja, não é possível classificar seres humanos de primeira linhagem - "pessoas", aqueles com uma perspectiva plausível de vida futura, e seres humanos com doenças ou malformações congênitas, seres de segunda linhagem "não pessoas". Nesse caso, seria aceitável conferir ao anencéfalo ou a uma pessoa que se encontre em EVP uma dignidade parcial, ou seja, que seria compatível com seu nível de consciência. No entanto, a idéia de dignidade parcial da pessoa humana que não se coaduna com o nível alcançado de desenvolvimento ético em termos universais.

\footnotetext{
${ }^{3}$ A despeito da discussão filosófica sobre a distinção entre ser humano e pessoa, particularmente as concepções formuladas por H. Tristam Engelhardt Jr. e Peter Singer, que consideram pessoa o ser humano com capacidade de reflexão e auto-consciência, neste trabalho adotamos a corrente filosófica, fundamentada em Sève, que confere a todos do gênero humano o status de pessoa, com exceção feita ao feto, que é entendido como pessoa em potencial.
} 
Desta forma, ao se tratar o neonato anencéfalo como uma pessoa, tem-se como decorrência o respeito inerente a essa condição, sendo assim inegável a necessidade de não concebê-lo como meio, mas sim como fim. A ética utilitarista de maximização de determinada grandeza, ou seja, se há um ser que fatalmente irá morrer e bebês que necessitam de órgãos para sobreviver, a resposta seria considerar o neonato anencéfalo como um meio de maximizar a felicidade, permitindo a sobrevivência de outros seres humanos. Contudo, considerando que o anencéfalo é uma pessoa com dignidade a ser respeitada, não é possível a alteração de um parâmetro de morte, válido para todos, apenas para transformá-lo em meio. Assim, na verdade, a mudança do critério de morte encefálica para a morte do neocórtex, teria como escopo transformar uma pessoa de fim em meio. O perigo de se alterar esse parâmetro para uma pessoa com uma determinada malformação não é apenas a possibilidade de se ampliar futuramente para outras que se encontrarem na mesma situação, mas sim, principalmente, de se permitir alterar um parâmetro válido para todos e em nível mundial com o fito de coisificar um ser humano. O problema está na motivação justificadora da alteração do parâmetro.

O respeito ao neonato anencéfalo perpassa pelo respeito a sua vida, independentemente da sua qualidade. Primeiramente, quem pode assegurar o que seja "qualidade" de vida para uma outra pessoa? Nesse sentido, parâmetros básicos de condições sócio-econômicas talvez possam ser levados em conta. Por exemplo, não ter alimento, roupa ou moradia são sinais patentes de uma vida sem qualidade. Mas quando se transporta essa percepção para o campo das condições de saúde torna-se muito subjetivo e imprudente tentar definir o que é qualidade de vida. Como questiona Sève, "quem pode estabelecer uma lista das anomalias congênitas que condenam a uma vida sem qualidade?" (SÈVE, Op. cit.). De qualquer forma, deve-se pensar que o respeito pela pessoa e sua vida não devem depender da suposta qualidade dessa: a condição da qualidade não pode ser fundamento para a suspensão do respeito à vida. No mesmo caminho da alteração do parâmetro de morte para o anencéfalo, a "ideologia da qualidade de vida metamorfoseia, assim, o ser humano em produto" (SÈVE, Op. cit.). A ética da qualidade de vida expõe, em última instância, a procura pela perfeição humana, pois os mais bem dotados e em condições saudáveis possuiriam uma qualidade de vida superior.

Desta forma, a ética da qualidade de vida padece do vício de quantificar o respeito por determinada pessoa em função da sua situação vital. Então, o que deve ser avaliado não é se aquela vida vale a pena ou não ser vivida, 
na medida em que "... esta noção foi formada no começo do século, por psiquiatras e juristas alemães, para justificar a eutanásia dos doentes mentais e dos deficientes..." (SÉVE, Op. cit.), mas sim, que toda pessoa possui um valor intrínseco, que impele as demais a agir com respeito.

A bioética de origem anglo-saxônica compraz-se com o recurso ao utilitarismo. Faz uso da balança de custos e benefícios (maior benefício para o maio número de pessoas) e ao conceito de qualidade de vida (SÈVE, Op. cit.). Assim, ocorre que é perceptível que bioeticistas de países periféricos utilizem essas categorias para avaliar situações que não se coadunam com aquele tipo de aporte teórico; portanto, é indispensável uma reflexão crítica sobre a importação de ferramentas teóricas. Argumentações no sentido de que a manutenção de pacientes que exigem cuidados excessivamente dispendiosos diminui o incremento de recursos para a coletividade devem ser vistas como reflexo de um pensamento utilitarista, a ser questionado e não simplesmente assumido como adequado. Conforme Sève, no utilitarismo não há qualquer questão de respeito, pois esse é dispensável para engendrar uma maximização do bem-estar da coletividade (SĖVE, Op. cit.).

Portanto, com base numa ética do respeito ao valor inerente à pessoa, não se pode concebê-la como coisa ou objeto de satisfação, de maximização de bem-estar. É sabida a quantidade diminuta de órgãos para bebês, bem como se pode presumir a angústia das famílias que têm seus filhos nessa situação. Entretanto, não há como se esquivar da tarefa precípua da bioética que é conferir efetividade à dignidade de cada pessoa, considerando-a como um valor a respeitar.

\section{Referências bibliográficas}

ANAMI, E. H. T. Implicações éticas do conceito de morte encefálica. In: Siqueira, J. E., Prota, L., Zancanaro, L. (Orgs.) Bioética: estudos e reflexões 2. Londrina, UEL: 78 $-92,2000$.

BOBBIO, N. Teoria do ordenamento jurídico. 9.ed. Brasília, UnB, 1997.

CASELLA, E. B. Morte encefálica e neonatos como doadores de órgãos. Disponível, em: <http://www.pediatriasaopaulo.usp.br >Acesso em, 17 de ago. 2004.

COMITATO NAZIONALE PER LA BIOETICA.Il neonato anecefalico e la donazione di organi. Disponível, em:< http://www.aido.it/trapianto-bioetica $>$. Acesso em: 24 de ago. 2004.

COSTA, A. A. Introdução ao direito: uma perspectiva ética das ciências jurídicas.1.ed. Porto Alegre, Sergio Fabris: 12, 2001. 
DICIONÁRIO MOSBBY. Barcelona, Elsevier Science. 6.ed. v. 1: 88, 1996.

FRANCO, A. C. Anencefalia fetal e doação de órgãos. Disponível, em: < http://www. ajd.org.br.> Acesso em: 17 ago. 2004.

GARRAFA, V. Caso Clínico. Disponível, em: < http://www.crmma.cfm.org.br.> Acesso em: 26 maio 2004.

GHERARDI, C. Muerte cerebral: una mirada crítica y reflexiva. Disponível, em: < http:/ / www.medicosecuador.com. > Acesso em: 17 agos. 2004.

INSTITUTO NACIONAL CENTRAL ÚNICO COORDINADOR DE ABLACIÓN E IMPLANTE Anencefalia e donación de órganos. Disponível, em:<http:// www.incucai.gov.ar> Acesso em: 24 de ago. 2004.

KIPPER, D. Caso Clínico. Disponível em: <http://www.crmma.cfm.org.br.> Acesso em: 26 maio 2004.

MOREIRA, N. Caso Clínico. Disponível em: <http://www.crmma.cfm.org.br. $>$ Acesso em: 26 maio 2004.

PIANETTI FILHO, G. Diagnóstico da morte cerebral.In: Alves, J. (Org.). Bioética. 2.ed. São Paulo, Fumarc: 182-188, 2001.

SEGRE, M. Caso Clínico. Disponível, em: < http://www.crmma.cfm.org.br> Acesso em: 26 de maio de 2004.

SÈVE, L. Para uma crítica da razão bioética. Lisboa, Piaget: 70-150, 1994.

Recebido em 4/4/2005

Aprovado em 19/4/2005 